\section{ANALYSING DRUGS AND PESTICIDES}

Gas Chromatographic Analysis of Drugs and Pesticides By Benjamin J. Gudzinowicz. (Chromatographic Science: A Series of Monographs.) Pp. ix +605 . (Arnold: London; Dekker: New York, 1967.) 260s.

THIs second volume in the series is self contained. The first part sets out the fundamentals of gas-liquid chromatography (GLC) and the principles of operation of five types of detector: thermoconductivity, hydrogen flame and argon ionization, electron affinity, and the relatively novel microcoulometric system. A further ninety pages are about qualitative techniques of correlation or of detecting functional groups. Regrettably, however, the basic principles and snags of quantitative analysis are condensed into a mere ten pages. The whole text is copiously documented with illustrative charts and chromatograms from original sources and numerous tables-although at least one is unnecessary. The exposition of tranquillizer structures in the otherwise over-brief quantitative section is dealt with more fully, including much of the author's own work, in the relevant following chapter.

The part on drugs begins appropriately with the advantages of GLC analysis of impurities in, and residues of, psychotropic materials. The structural classification of phenothiazine and related tranquillizers, however, is over simplified and lacks recent variants that should be equally amenable to the techniques described. There is a useful account of correlation within a series of $t_{r}$ with molecular weight and boiling point/melting point, and Martin's table of molecular increments is reprinted. The considerable work on barbiturates and their pyrolysates is reviewed, although only three references postdate 1963 . While more complex alkaloids are dismissed briefly, sympathomimetic amines and tryptamine bases are well covered. Forensic analysts will be interested in the report on a comprehensive series of morphine bases and the account of some of the earlier studies on cannabis constituents, although it was compiled before the recent advances by Walker, and by Fish, and their respective co-workers. Further chapters include short references to GLC methods for antihistamines, low volatility anaestheties, certain vitamins (but are these strictly drugs?), anticoagulants, salicylate antipyretics, and various terpenes and sapogenins.

Whether the high price of the book would have been proportionately reduced by removing the one third that describes fundamentals of apparatus, detection and techniques is arguable. Undoubtedly the second part (220 pages), which reviews an important aspect of drug analysis hitherto without adequate recognition, is valuable. On the other hand, pesticide and herbicide workers may feel that their interests in this field (which are given 160 pages) have been satisfactorily served elsewhere. In short, if this volume, like its predecessor, had appeared in parts, it may be that many pharmaceutical analysts could have dispensed with the remainder.

G. F. Phillits

\section{AIR POLLUTION}

\section{Air Pollution}

Edited by Arthur C. Stern. Vol. 1: Air Pollution and its Effects. Pp. xix + 694. 261s. Vol. 2: Analysis, Monitoring, and Surveying. Pp. xix +684 . 326s. 8d. (Environmental Science: An Interdisciplinary Monograph Series.) (Academic Press: New York and London, 1968.)

Since the publication of the two-volume first edition of this excellent treatise on air pollution, so much new material has become available that it has been necessary to use three volumes for the second edition. This review covers the first two volumes of the new edition now available.
The editor, Arthur C. Stern, who has had a long and wide experience of investigations of problems of mitigation of air pollution, is with the Center for Air Pollution Control in the US Department of Health, Education and Welfare, Washington. The thirty-seven authors he has brought together to write the thirty-one chapters in the first two volumes are all specialists concerned with various aspects of the subject on which a large amount of work at considerable expense has been undertaken in the United States, particularly during the past two decades.

Volume 1 contains fifteen chapters divided into three main parts. The first part contains a general introductory chapter followed by chapters on gaseous pollutants, particulate matter, radioactive pollution, the chemical and photochemical reactions of the pollutants in the air with one another and with the normal constituents of the air, and on natural scavenging processes. In the second part there are chapters on meteorology in relation to air pollution, dispersion in the atmosphere of discharges from chimneys, climatology, and the meteorological management of air pollution. The third part covers the effects of various pollutants on the physical properties of the atmosphere, for example, on visibility, on vegetation, on animals and on human health, and on a number of materials, including materials of construction. Brief consideration is given to the economic effects of air pollution and its prevention.

In volume 2 there are sixteen chapters grouped into three parts covering methods of sampling, measurement, identification and the chemical, physical and microscopical examination of the various gaseous pollutants and particulate matter, monitoring of airborne radioactivity, measurement of odours, meteorological measure ments, community air pollution surveys, examination and measurement of pollutants at the sources of emission, legislative measures and systems of inspection and control.

At the end of each chapter, with the exception of the first introductory chapter of volume $I$, there is a useful list of references to the literature of the subject; in all, there is a total of more than 2,000 references.

Both volumes are well produced and are a credit, to the printers and publishers as well as to the authors, but they are somewhat high in price. It is difficult to understand why the price of the second volume is over $£ 3$ greater than that of the first as the numbers of pages and diagrams are about the same in each of the two volumes.

The two volumes of this new second edition will be of great service to all who are concerned with the many aspects and problems of mitigation of air pollution.

A. Parker

\section{Announcements}

Dr J. B. Adams, member for research at the UKAFA, has been elected chairman of the Committee of Management of the Science of Science Foundation. Other new members are: Mr Michael Shanks, dircetor of marketing services and economic planning, British Leyland Motor Corporation; Dr Herbert Coblans of ASLIB; Professor K. W. Keohane, professor of science education at Chelsea College of Science and Technology; Mr John Wren-Lewis of the EVR Partnership and Mr Heinz Wolff, director of Biomedical Engineering Division, Medical Research Council.

Dr Philip Ross of Potomac, Maryland, has been elected president of the newly established International Sugar Research Foundation, Inc., and Dr John L. Hickson has been elected vice-president and director of research. The Vernon Prize of the National Institute of Industrial Psychology has been awarded to W. T. Singleton, professor of applied psychology at the University of Aston in Birmingham, in recognition of his research in industrial psychology and physiology. The institute's 